\title{
BMJ Open Hyponatraemia, hyperglycaemia and worsening renal function at first blood sample on emergency department admission as predictors of in-hospital death in patients with dyspnoea with suspected acute heart failure: retrospective observational analysis of the PARADISE cohort
}

Tahar Chouihed, ${ }^{1,2,3}$ Aurélien Buessler, ${ }^{1}$ Adrien Bassand, ${ }^{1,2}$ Deborah Jaeger, ${ }^{1,2}$ Jean Marc Virion, ${ }^{4,5}$ Lionel Nace, ${ }^{6}$ Françoise Barbé, ${ }^{7}$ Sylvain Salignac, ${ }^{8}$ Patrick Rossignol, ${ }^{2,3,9}$ Faiez Zannad, ${ }^{2,3,9}$ Nicolas Girerd ${ }^{2,3,9}$

To cite: Chouihed T, Buessler A, Bassand A, et al. Hyponatraemia, hyperglycaemia and worsening renal function at first blood sample on emergency department admission as predictors of in-hospital death in patients with dyspnoea with suspected acute heart failure: retrospective observational analysis of the PARADISE cohort. BMJ Open 2018;8:e019557. doi:10.1136/ bmjopen-2017-019557

- Prepublication history for this paper is available online. To view these files, please visit the journal online (http://dx.doi. org/10.1136/bmjopen-2017019557).

Received 20 September 2017 Revised 7 February 2018 Accepted 23 February 2018

Check for updates

For numbered affiliations see end of article.

Correspondence to

Dr Tahar Chouihed;

t.chouihed@gmail.com

\section{ABSTRACT}

Objectives To assess the prognostic value of hyponatraemia, hyperglycaemia and impaired estimated glomerular filtration rate (eGFR) in predicting in-hospital death in patients with acute heart failure (AHF) admitted for acute dyspnoea in the emergency department.

Design Retrospective observational study.

Setting Emergency Department of the University Hospital of Nancy. Data were collected from August 2013 to October 2015.

Participants The analysis included 405 patients with AHF admitted for acute dyspnoea in an emergency department. Results The population was elderly (mean age 82 years), $20.1 \%$ had hyponatraemia, $45.1 \%$ had hyperglycaemia and $48.6 \%$ had eGFR $<50 \mathrm{~mL} / \mathrm{min} / 1.73 \mathrm{~m}^{2}$. Sixty-one patients $(15.1 \%)$ died in hospital, mostly due to cardiac aetiology (58.3\%). In multivariable analysis adjusted for key potential confounders, adjusted hyponatraemia $(\mathrm{OR}=2.40$, (1.16 to 4.98$), p=0.02$ ), hyperglycaemia ( $O R=2.00,1.06$ to $3.76, p=0.03)$ and eGFR $<50 \mathrm{~mL} / \mathrm{min} / 1.73 \mathrm{~m}^{2}(\mathrm{OR}=1.97$ (1.00 to 3.80$\left.), p=0.04^{\star}\right)$ were all identified as significant independent predictors of in-hospital death.

Conclusions Results of basic routine laboratory tests (hyponatraemia, hyperglycaemia and impaired eGFR) performed on admission in the emergency department are independently associated with in-hospital death. These inexpensive tests, performed as early as patient admission in the emergency department, could allow the early identification of patients admitted for AHF who are at high risk of in-hospital death.

Trial registration number NCT02800122.

\section{INTRODUCTION}

Dyspnoea is one of the most frequent causes of admission in the emergency department

\section{Strengths and limitations of this study}

- This study focuses on simple biomarkers readily available in the emergency department.

- Given that our study had broad inclusion criteria and that all patients having these criteria could be exported from electronic patient files, our data represent a fair reflection of the clinical practice of large emergency centres in France.

- The retrospective design of this study is a limitation and the absence of residual confounding cannot be ascertained.

- Out-of-hospital mortality was not available.

- Brain natriuretic peptide was not available in all patients.

(ED). ${ }^{1}$ Acute heart failure (AHF) is one of the main aetiologies of acute dyspnoea, ${ }^{2} 3$ and is the most common aetiology for hospitalisation in patients aged 65 years or older. Importantly, at presentation, acute dyspnoea is often the cause of several coexisting aetiologies, and prognosis assessment is therefore more difficult in the ED. ${ }^{4}$ The prognosis for AHF remains poor with an in-hospital mortality of $8 \% .^{5-7}$

A number of tools have been developed to assess risk at an early stage during AHF hospitalisation, including clinical findings, imaging and biological factors. However, these risk-stratifying tools have been primarily derived from populations with isolated AHF included in cardiology units. As a result, the 


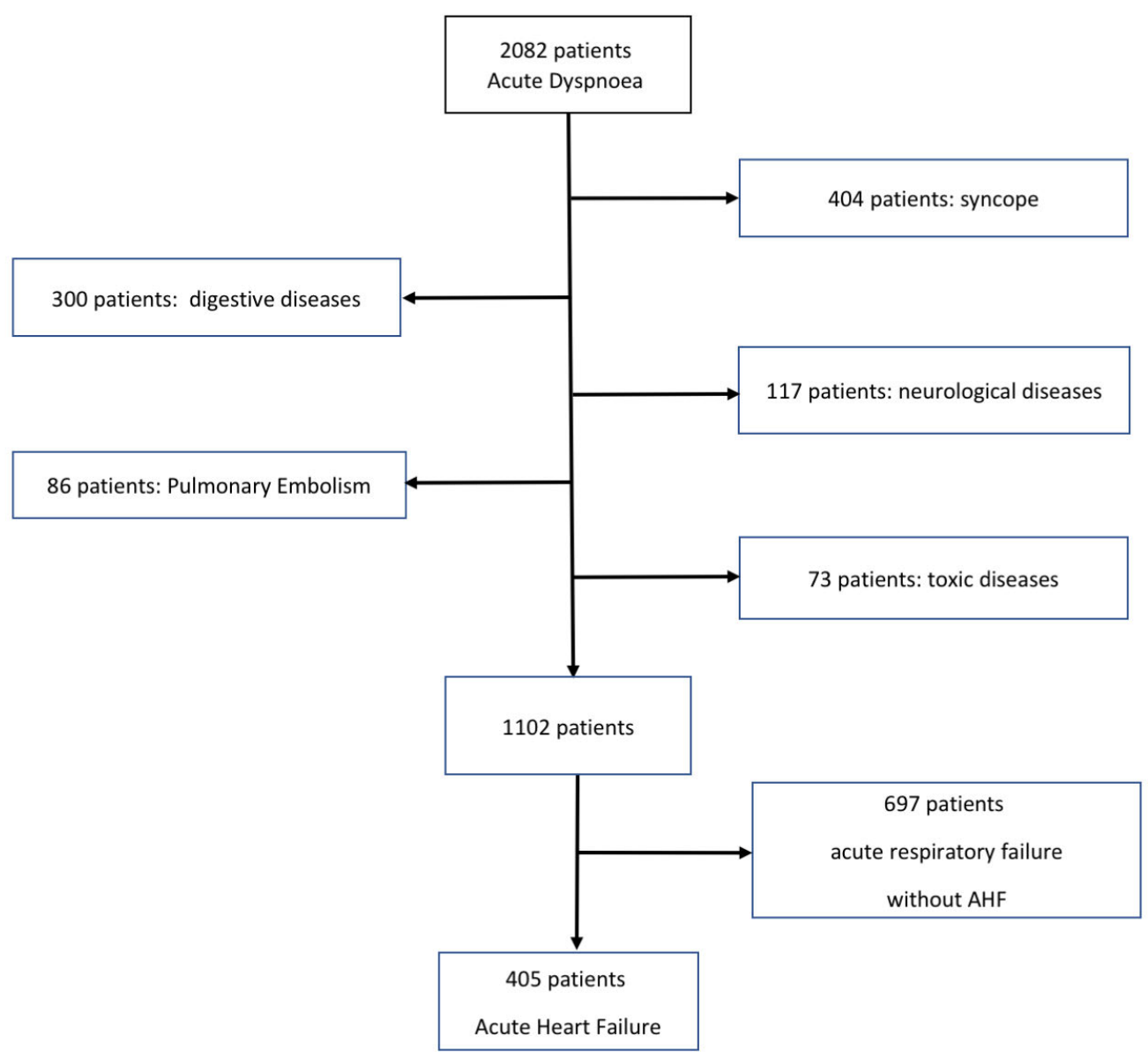

Figure 1 Flow chart. AHF, acute heart failure.

prognosis factors relevant to an unselected population of patients with AHF, with either isolated AHF or AHF associated with coexisting causes of acute dyspnoea, have been sparsely assessed.

Simple biomarkers such as hyponatraemia, hyperglycaemia and renal dysfunction have been shown to be associated with short-term prognosis in patients admitted in cardiology units for AHF. ${ }^{8-10}$ Hyponatraemia is the most common electrolyte abnormality in patients hospitalised with $\mathrm{AHF}^{11}$ with a prevalence of $19 \%-25 \%$. Notwithstanding, the importance of assessing patient prognosis at ED admission for AHF remains paramount. As suggested above, most studies have investigated this biomarker in an in-hospital setting, However, the prognostic factor of these markers in the ED, within hours of admission, in patients with suspected AHF, has been insufficiently studied.

In light of the above, the present study assessed the predictive value of hyponatraemia, hyperglycaemia and renal function at first blood sample in patients admitted in the ED for acute dyspnoea due to AHF.

\section{METHOD}

\section{Study population and design}

The 'Pathway of dyspneic patients in Emergency' (PARADISE) cohort (NCT02800122) was constituted from the hospital's electronic database which was used to search for the records of all patients fulfilling the required characteristics of the study population.

Inclusion criteria consisted of all patients with acute dyspnoea aged 18 year or older admitted in the academic ED of the Nancy University Hospital (France) over a 27-month period from 1 August 2013 to 31 October 2015. Among the 2082 patients with acute dyspnoea admitted over the studied time period, 405 patients (19.5\%) were considered as having AHF as the sole or associated cause of admission in the ED (figure 1). The diagnosis was retrieved from the patients' medical report with final diagnosis at hospital discharge according to the International Classification Diseases code (I.50.0, I50.1, I50.9 and J81).

Medical history, clinical parameters, laboratory results, treatment received in the ED and in-hospital outcome were retrieved from the patients' medical record. In keeping with data protection requirements, the PARADISE cohort was approved by the Commission d'Informatique et Libertés under number: R2016-08.

\section{Biochemical analyses}

The determinations of natraemia, glucose and creatinine concentrations by ion selective electrodes and enzymatic methods were performed on Beckman Coulter AU Clinical Chemistry analyzers. Natraemia was corrected for blood 
glucose using the following formula: corrected serum sodium $(\mathrm{mmol} / \mathrm{L})=$ measured serum sodium $-1.6(1-$ blood glucose $(\mathrm{g} / \mathrm{L}))$. Estimated glomerular filtration rate (eGFR) was calculated using the MDRD formulas. To account for diabetic status, as used by others, ${ }^{12}$ hyperglycaemia was defined as a blood glucose $>1.26 \mathrm{~g} / \mathrm{L}$ for diabetes-free patients and $>1.8 \mathrm{~g} / \mathrm{L}$ for patients with diabetes. Brain natriuretic peptide (BNP) and/or troponin were measured at the time of emergency management.

\section{Radiography}

Chest X-rays were interpreted by emergency ward physicians, and were coded as follows: normal, pulmonary infection, heart failure (including pleural effusion) and both infection and heart failure.

\section{Statistical analyses}

Continuous variables are presented as mean and SD; categorical variables are presented as numbers and percentage of patients. The continuous variables were analysed using Student's t-test, while comparisons between categorical variables were performed with the $\chi^{2}$ test or Fisher's exact test as appropriate.

Associations of biological variables with in-hospital death were derived from univariable and multivariable logistic regression. Models of increasing complexity were used. Adjustment variables, a priori selected on clinical relevance (as previously used by our group), ${ }^{13}$ included biological variables (natraemia, blood glucose and eGFR-in models in which the variable was not the primary exposure variable), age, systolic blood pressure (SBP), diabetes and BNP.

The reported $p$ values are two-sided and a $p$ value of $<0.05$ was considered to indicate statistical significance. Statistical analyses were performed using SAS/STAT software, V.9.4 of the SAS System for Windows.

\section{RESULTS}

\section{Descriptive characteristics}

Overall, the population was elderly (mean age $82.1 \pm 10.7$ years), predominantly woman (60.7\%), with a high proportion of comorbidities. More than one-third of patients were admitted in intensive care units (ICUs). SBP was mainly in the hypertensive range $(145.6 \pm 32.2 \mathrm{~mm} \mathrm{Hg})$. A majority of patients had an eGFR $\geq 50 \mathrm{~mL} / \mathrm{min} / 1.73 \mathrm{~m}^{2}(50.8 \%)$ whereas a corrected natraemia level $<136 \mathrm{mmol} / \mathrm{L}$ was observed in $21.5 \%$ and a high blood glucose level in $43.9 \%$ (table 1). In-hospital mortality rate was $15.1 \%(\mathrm{n}=61)$.

Detailed characteristics according to natraemia, hyperglycaemia and eGFR status are presented in table 1 . There were no stringent differences between the groups with normal and abnormal laboratory values except for SBP, which was lower in patients with natraemia $<136$ and eGFR $<50$, but higher in patients with hyperglycaemia. BNP levels were similar across all groups except for higher BNP values in patients with eGFR $>50$. Patients with natraemia $<136 \mathrm{mmol} / \mathrm{L}$ had a much higher mortality rate than patients with normonatraemia $(24.1 \%$ vs $12.6 \%$, $\left.\mathrm{p}=0.01^{*}\right)$.

\section{Correlations with in-hospital mortality}

In univariable analysis, hyponatraemia was significantly associated with in-hospital mortality $(\mathrm{OR}=2.61$, (1.40 to 4.85$\left.), \quad \mathrm{p}<0.01^{*}\right)$ whereas eGFR $<50 \mathrm{~mL} /$ $\mathrm{min} / 1.73 \mathrm{~m}^{2} \quad(\mathrm{OR}=1.65, \quad(0.95$ to 2.88$), \mathrm{p}=0.08)$ and hyperglycaemia ( $\mathrm{OR}=1.56,(0.90$ to 2.72$), \mathrm{p}=0.12)$ were not associated with outcome (table 2). After adjustment for potential confounders (age, SBP, diabetes and BNP) and other routine laboratory variables, hyponatraemia $(\mathrm{OR}=2.40, \quad(1.16$ to 4.98$), \mathrm{p}=0.02 *)$, hyperglycaemia $(\mathrm{OR}=2.00$, (1.06 to 3.76$), \mathrm{p}=0.02 *)$ and eGFR $<50 \mathrm{~mL} /$ $\min / 1.73 \mathrm{~m}^{2}\left(\mathrm{OR}=1.97,(1.00\right.$ to 3.80$\left.), \mathrm{p}=0.04^{*}\right)$ were all significantly associated with a two-fold increase in the risk of in-hospital mortality (table 2).

Importantly, the association between hyperglycaemia and outcome was not dependent on diabetic status ( $p$ for interaction between diabetic status and hyperglycaemia $=0.61$ ).

\section{DISCUSSION}

The main findings of this study are that routine laboratory tests such as hyponatraemia, hyperglycaemia and reduced eGFR are strong and independent predictors of in-hospital mortality in the specific setting of patients with AHF admitted for acute dyspnoea in the ED.

Altered cardiac function triggers extrinsic and intrinsic mechanisms aimed at maintaining adequate cardiac output. One such mechanism is peripheral adaptation. Indeed, decreased cardiac output leads to neurohumoral system (rennin-angiotensin-aldosterone and arginine vasopressin (AVP)) activation in order to preserve plasma volume and maintain organ perfusion pressure. Such activation represents one of the major characteristics of heart failure and can be deleterious in the long term. Angiotensin II is a very powerful vasoconstrictor which additionally induces, via aldosterone, substantial hydro-sodium retention. AVP is a powerful vasoconstrictor that also features antidiuretic properties that can ultimately promote fluid retention and hyponatraemia. AVP is stimulated at the final heart failure stage. It is therefore possible to interpret hyponatraemia as a neurohumoral activation marker of advanced heart failure. Our study results confirm that hyponatraemia, measured as early as the first blood sample, is a risk factor for in-hospital mortality. It is thus important, at the ED, to detect the hyponatraemia in patients admitted with acute AHF.

Cardiorenal syndrome results in kidney damage associated with renal dysfunction. According to the definition, the incidence of worsening renal function during AHF is $20 \%-30 \%$. Systemic congestion is an important predictor of worsening renal function during AHF. Kidney function degrades through several mechanisms (reduced renal blood flow, renal hypoxia, increased interstitial pressure 


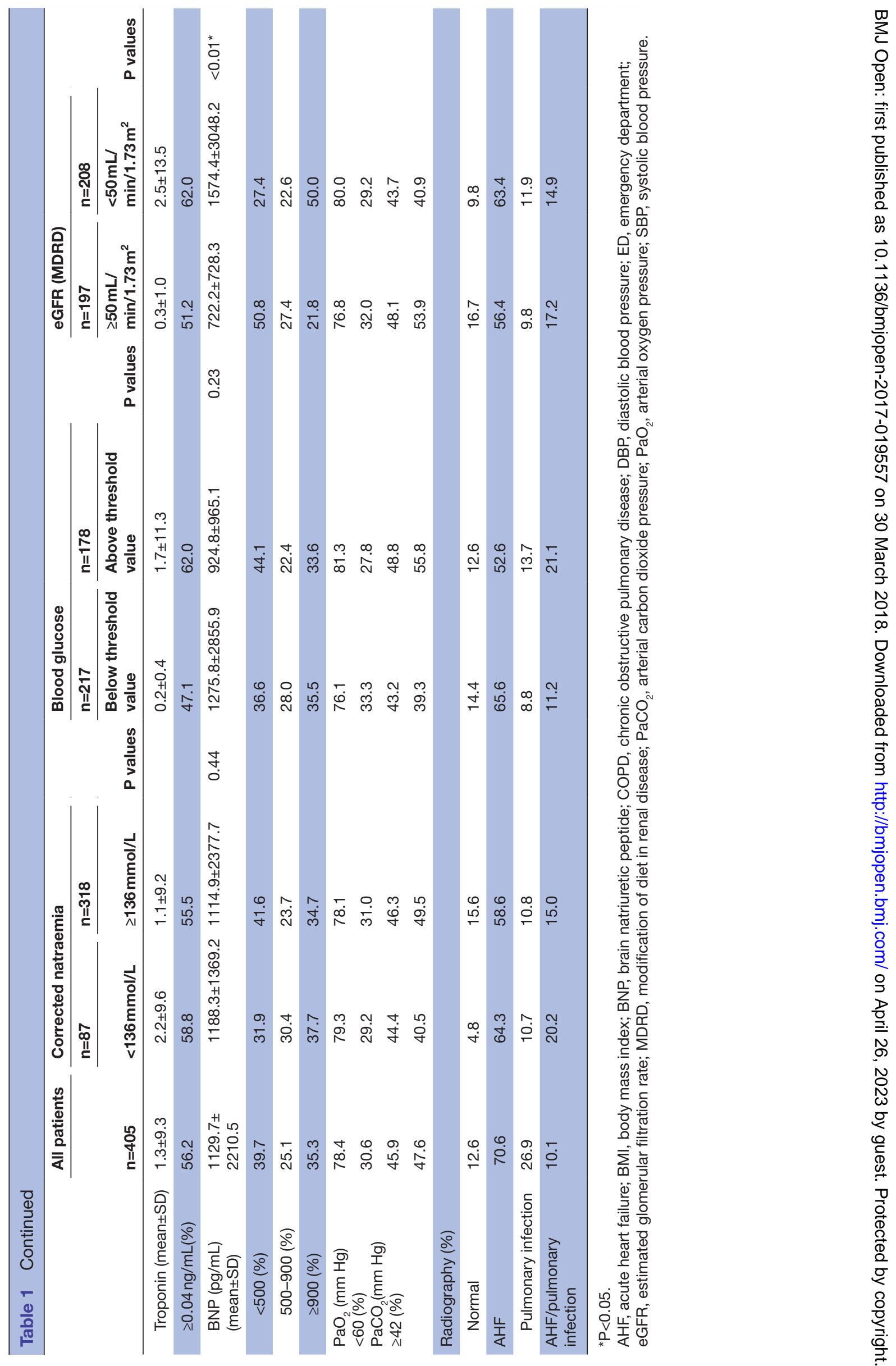


Table 2 Laboratory analysis: mortality predictive factors-multivariate regression

\begin{tabular}{|c|c|c|c|c|}
\hline & \multicolumn{2}{|c|}{ Univariable regression } & \multicolumn{2}{|c|}{ Multivariable regression } \\
\hline & OR (Cl 95\%) & $P$ values & OR (Cl 95\%) & $P$ values \\
\hline \multicolumn{5}{|l|}{ Corrected natraemia } \\
\hline$\geq 136 \mathrm{mmol} / \mathrm{L}$ & 1 (Ref) & Ref & 1 (Ref) & Ref \\
\hline$<136 \mathrm{mmol} / \mathrm{L}$ & 2.61 (1.40 to 4.85$)$ & $0.002^{*}$ & 2.40 (1.16 to 4.98$)$ & $0.02^{*}$ \\
\hline \multicolumn{5}{|l|}{ Blood glucose (g/L) } \\
\hline Below threshold value & 1 (Ref) & Ref & 1 (Ref) & Ref \\
\hline Above threshold value & 1.56 (0.90 to 2.72$)$ & 0.12 & 2.00 (1.06 to 3.76$)$ & $0.03^{*}$ \\
\hline \multicolumn{5}{|l|}{ MDRD $\dagger$} \\
\hline$\geq 50 \mathrm{~mL} / \mathrm{min} / 1.73 \mathrm{~m}^{2}$ & 1 (Ref) & Ref & 1 (Ref) & Ref \\
\hline$<50 \mathrm{~mL} / \mathrm{min} / 1.73 \mathrm{~m}^{2}$ & 1.65 (0.95 to 2.88 ) & 0.08 & $1.97(1.00$ to 3.80$)$ & $0.04^{*}$ \\
\hline
\end{tabular}

Multivariable model includes laboratory variables, age, SBP, diabetes and BNP.

${ }^{*} \mathrm{P}<0.05$.

†MDRD, creatinine clearance $\left(\mathrm{mL} / \mathrm{min} / 1.73 \mathrm{~m}^{2}\right)$.

BNP, brain natriuretic peptide; MDRD, modification of diet in renal disease; SBP, systolic blood pressure.

and renal interstitial fibrosis) and represents an independent risk factor during AHF. Independently of the definition used, worsening renal function is common in patients admitted for AHF in the emergency room. In the DefSSICA study, a prospective survey conducted in 26 EDs in France, nearly $30 \%$ of the patients admitted for AHF presented renal impairment (median eGFR=50 (35-69) $\mathrm{mL} / \mathrm{min} / 1.73 \mathrm{~m}^{2}$ ), whereas patients without AHF had better renal function (median eGFR=65 (42-92) mL/ $\left.\min / 1.73 \mathrm{~m}^{2}, \mathrm{p}<0.001\right)$. The occurrence of worsening renal function has been associated with an increased risk of hospital readmission and both in-hospital and postdischarge mortality. Such condition hence warrants close monitoring from the first emergency contact onward.

\section{Prognostic value of natraemia for patients with AHF admitted in the ED}

In our cohort, natraemia $<136 \mathrm{mmol} / \mathrm{L}$ was found to be frequent $(20.1 \%)$ in patients with AHF admitted for acute dyspnoea and associated with a two-fold increase in the risk of in-hospital mortality $(\mathrm{OR}=2.40$, (1.16 to 4.98$]) \mathrm{p}=0.02 *)$. Several studies have investigated this electrolyte balance disorder in the setting of cardiology wards in patients with typically isolated AHF. ${ }^{14-16}$ In these previous reports, hyponatraemia was similarly common $(19 \%-25 \%)$ in patients with isolated $\mathrm{AHF}^{17}$ and associated with a higher risk of short-term and medium-term mortality $(6.0 \%$ CI $95 \%$ (5.5 to 6.5 vs $3.2 \%$ (3.0 to 3.4$), \mathrm{p}<0.0001 \%$ and $12.4 \%$ CI $95 \%$ ( 10.0 to 14.9 ) vs $7.6 \%$ (6.2 to 8.1$)$, $\mathrm{p}<0.0001$ ), respectively in the OPTIMIZE-HF study. ${ }^{18}$ Compared with this previously reported population, the present population was much older (82 vs 73 years old) and had a much higher mortality rate (in-hospital mortality $15.1 \%$ vs $<4 \%$ in OPTIMIZE-HF). Despite this much greater risk profile, natraemia $<136$ remained strongly and independently associated with mortality and thus highly relevant in the setting of patients with acute dyspnoea admitted in the ED.

Prognostic value of eGFR for patients with AHF admitted in the ED

An eGFR $<50 \mathrm{~mL} / \mathrm{min} / 1.73 \mathrm{~m}^{2}$ was also found to be a significant predictor of in-hospital death $(\mathrm{OR}=1.97$, (1.00 to 3.80$), p=0.04)$. Previous reports showed that worsening renal function during diuretic, ACE inhibitor or vasodilator therapy was not a strong predictor of adverse mid-term outcome. ${ }^{19}$ Worsening renal function is often a common accompanying feature of decongestion, ${ }^{20}$ with certain metrics of decongestion such as haemoconcentration being protective in the setting of AHF. ${ }^{21}$ The present study highlights a strong association between admission eGFR $<50 \mathrm{~mL} / \mathrm{min} / 1.73 \mathrm{~m}^{2}$ and in-hospital mortality.

This finding reinforces the strong prognostic value of admission renal function for very short-term outcome, likely due to the difficulty in treating congestion in patients with impaired renal function..$^{22}$ Importantly, the use of dialysis may be hampered in elderly patients with aggravating renal function during the course of hospital stay, which could partly explain this strong association with adverse outcome.

\section{Prognostic value of hyperglycaemia for patients with AHF admitted in the ED}

Hyperglycaemia was similarly found to be an independent predictor of in-hospital death in our population of patients with AHF admitted for acute dyspnoea $(\mathrm{OR}=2$, (1.06 to 3.76), $\mathrm{p}=0.03$ ). Several studies have shown that hyperglycaemia is a prognostic factor in AHF, even in patients admitted for AHF in the ED. ${ }^{12} 2324$ Our results are thoroughly in keeping with the report of Mebazaa et $a l$ which showed a significant and independent association between hyperglycaemia and short-term mortality 
at 30 days $(\mathrm{OR}=2.19$, CI $95 \%(1.69$ to 2.83$) \mathrm{p}<0.001) .^{12}$ Kattel et al furthermore showed that hyperglycaemia also had an impact on long-term prognosis (ie, 1.8 years) ${ }^{25}$ The present findings further demonstrate that hyperglycaemia also has a significant prognostic impact on very early outcome such as in-hospital death.

\section{The specific setting of patients with AHF admitted for acute dyspnoea in the ED}

The prognostic value of blood glucose levels, natraemia and renal function has already been shown in other studies, although mainly in patients with usually isolated AHF, with or without acute dyspnoea, and primarily in cardiology units. Similarly, most predictive scores have stemmed from patients admitted to cardiology units and have assessed various associations with mild to long-term outcome. ${ }^{26}$ Importantly, the only AHF in-hospital mortality risk score developed in the ED, namely the Emergency Heart Failure Mortality Risk Grade (EHMRG) score, included creatinine (but not eGFR) and furthermore did not consider natraemia or blood glucose. ${ }^{27}$ To our knowledge, the present study is the first joint analysis of routine laboratory tests to include eGFR, natraemia and blood glucose in the very specific setting of acute dyspnoea in patients with AHF admitted to the ER.

We believe that the settings in which predictors of outcome are studied is highly relevant for AHF. Indeed, as previously demonstrated by our group in the DEFSICA study, ${ }^{3}$ patients admitted for acute dyspnoea in the ED are often older, sicker and have a higher degree of associated comorbidities as well as associated acute dyspnoea aetiology than patients admitted in cardiology wards. Importantly, only a small proportion of our population was admitted to a cardiology ward after ED stay $(<20 \%)$, clearly underscoring the selection bias derived from data acquired solely in cardiology departments. Despite this comorbid state as well as the substantial mortality of this population $(>15 \%)$, simple laboratory tests such as eGFR, natraemia and blood glucose remained nonetheless strong predictors of outcome and should stoutly be considered in future risk-stratifying tools in patients with acute dyspnoea with suspected AHF admitted in the ER. Such risk-stratifying tools are warranted given the unacceptable in-hospital mortality observed in these patients, which is currently much higher than patients admitted for acute myocardial infarction. ${ }^{28}$

Assessment of natriuretic peptides (NP) is particularly relevant in $\mathrm{AHF}^{29}$ as demonstrated in the PRIDE study which showed that NP was superior to clinical evaluation for risk stratification. ${ }^{30}$ Importantly, we provide evidence for the strong and independent association of eGFR, natraemia and blood glucose even when adjusting for BNP values. Several other biomarkers have been shown to be useful prognostic factors, including troponin levels. ${ }^{31}$ However, these latter biomarkers are not currently used in all patients admitted for acute dyspnoea, whereas the basic laboratory tests targeted herein are available in virtually all patients admitted in the ED. In addition, BNP and troponin results are usually delivered several hours after admission whereas usual laboratory workup is typically delivered within 1 hour of admission. As a result, using these routine test results could allow for a faster risk stratification of patients with AHF admitted for acute dyspnoea, and could guide toward rapid admission to a specialised medical unit such as an ICU or cardiac care unit.

\section{Limitations}

The main limitations of this study are that, given its limited sample size and single-centre retrospective nature, the present results require external validation. Nevertheless, our study would appear of key interest for such external validation and suggests that routine laboratory tests may represent valuable candidate variables for future risk-stratifying tools dedicated to patients with AHF admitted in the ED. Second, literature has already shown that there is a 'weekend effect' for patients admitted to ED on weekends and public holidays versus those admitted on other days. ${ }^{32}$ Unfortunately, such information is not available is our dataset. Third, we did not have information regarding hospital length of stay, which could have been an adjustment factor. However, this limitation is not of key importance in our analysis since only the single and first value at admission to the ED was considered and not an analysis of the variation at various times during hospital stay.

\section{CONCLUSION}

Our study highlights the strong association of hyponatraemia, hyperglycaemia and renal dysfunction at admission in patients with AHF admitted in the ED for acute dyspnoea. These routine laboratory results should hence not be overlooked as risk-stratifying tools in this specific population remain to be constructed and validated.

\section{Author affiliations}

${ }^{1}$ Emergency Department, University Hospital of Nancy, Nancy, France ${ }^{2}$ Faculté de Médecine, INSERM, Centre d'Investigations Cliniques Plurithématique 1433, Institut Lorrain du Cœur et des Vaisseaux, Vandoeuvre les Nancy France Groupe choc, INSERM U1116, Nancy, France

${ }^{3}$ F-CRIN INI-CRCT (Cardiovascular and Renal Clinical Trialists), Nancy, France

${ }^{4}$ France Inserm, CIC-1433 Epidemiologie Clinique, Nancy, France

${ }^{5}$ University Hospital of Nancy, Pôle S2R, Epidémiologie et Evaluation Cliniques, Nancy, France

${ }^{6}$ Intensive Care Unit, University Hospital of Nancy, Nancy, France

${ }^{7}$ Biochimie, Biologie moléculaire, Nutrition, Métabolisme, Hôpital de Brabois, CHRU Nancy, Nancy, France

${ }^{8}$ Hématologie, Hôpital de Brabois, CHRU Nancy, Nancy, France

${ }^{9}$ Pôle de Cardiologie, Institut Lorrain du Cœur et des Vaisseaux, CHRU Nancy, Nancy, France

Acknowledgements We thank Pierre Pothier for editing the manuscript and Pierre Edouard Bollaert for providing expert advice.

Contributors TC, ABu, ABa, DJ, PR, FZ and NG drafted the manuscript for important intellectual content. LN provided the study clinical data. ABu and JMV coordinated the data management and performed the data analysis. FB and SS coordinated the biological analysis dataset. All authors read and approved the final manuscript. 
Funding Results incorporated in this article received funding from the Investments for the Future program under grant agreement No ANR-15-RHU-0004.

Competing interests TC and NG have received Board Membership Fees from Novartis. PR received fees from Relypsa. FZ has received fees for serving on the board of Boston Scientific; consulting fees from Novartis, Takeda, AstraZeneca, Boehringer Ingelheim, GE Healthcare, Relypsa, Servier, Boston Scientific, Bayer, Johnson and Johnson, and Resmed; and speakers' fees from Pfizer and AstraZeneca. FZ and PR are co-founders of CardioRenal diagnostics.

Patient consent Detail has been removed from this case description/these case descriptions to ensure anonymity. The editors and reviewers have seen the detailed information available and are satisfied that the information backs up the case the authors are making.

Ethics approval In keeping with data protection requirements, the PARADISE "Pathway of dyspneic patients in Emergency" cohort was approved by the Commission d'Informatique et Libertés (CIL) under number: R2016-08.

Provenance and peer review Not commissioned; externally peer reviewed.

Data sharing statement № additional data are available.

Open Access This is an Open Access article distributed in accordance with the Creative Commons Attribution Non Commercial (CC BY-NC 4.0) license, which permits others to distribute, remix, adapt, build upon this work non-commercially, and license their derivative works on different terms, provided the original work is properly cited and the use is non-commercial. See: http://creativecommons.org/ licenses/by-nc/4.0/

(C) Article author(s) (or their employer(s) unless otherwise stated in the text of the article) 2018. All rights reserved. No commercial use is permitted unless otherwise expressly granted.

\section{REFERENCES}

1. Prekker ME, Feemster LC, Hough CL, et al. The epidemiology and outcome of prehospital respiratory distress. Acad Emerg Med 2014;21:543-50.

2. Kelly AM, Holdgate A, Keijzers G, et al. Epidemiology, prehospital care and outcomes of patients arriving by ambulance with dyspnoea: an observational study. Scand J Trauma Resusc Emerg Med 2016;24:113-9.

3. Chouihed T, Manzo-Silberman S, Peschanski N, et al. Management of suspected acute heart failure dyspnea in the emergency department: results from the French prospective multicenter DeFSSICA survey. Scand J Trauma Resusc Emerg Med 2016;24:112-8.

4. Ray P, Birolleau S, Lefort $Y$, et al. Acute respiratory failure in the elderly: etiology, emergency diagnosis and prognosis. Crit Care 2006;10:R82.

5. Zannad F, Mebazaa A, Juillière $Y$, et al. Clinical profile, contemporary management and one-year mortality in patients with severe acute heart failure syndromes: The EFICA study. Eur J Heart Fail 2006;8:697-705.

6. Frigerio M, Mazzali C, Paganoni AM, et al. Trends in heart failure hospitalizations, patient characteristics, in-hospital and 1-year mortality: A population study, from 2000 to 2012 in Lombardy. Int $J$ Cardiol 2017;236:310-4.

7. Harjola P, Boyd J, Tarvasmäki T, et al. The impact of emergency medical services in acute heart failure. Int J Cardiol 2017;232:222-6.

8. Omar HR, Guglin M. Community acquired versus hospital acquired hyponatremia in acute heart failure: Association with clinical characteristics and outcomes. Int J Cardiol 2016;225:247-9.

9. Targher G, Dauriz M, Tavazzi L, et al. on behalf of IN-HF Outcom Investigators. Prognostic impact of in-hospital hyperglycemia in hospitalized patients with acute heart failure: Results of the IN-HF (Italian Network on Heart Failure) Outcome registry. International Journal of Cardiology 2016;206:587-93.

10. Weidmann ZM, Breidthardt T, Twerenbold R, et al. Prediction of mortality using quantification of renal function in acute heart failure. Int J Cardiol 2015;201:650-7.
11. Farmakis D, Filippatos G, Parissis J, et al. Hyponatremia in heart failure. Heart Fail Rev 2009;14:59-63.

12. Mebazaa A, Gayat E, Lassus J, et al. Association between elevated blood glucose and outcome in acute heart failure: results from an international observational cohort. J Am Coll Cardiol 2013;61:820-9.

13. Coiro S, Rossignol P, Ambrosio G, et al. Prognostic value of residual pulmonary congestion at discharge assessed by lung ultrasound imaging in heart failure: Prognostic value of B-lines after discharge from HF hospitalisation. European Journal of Heart Failure 2015;17:1172-81.

14. Saepudin S, Ball PA, Morrissey H. Hyponatremia during hospitalization and in-hospital mortality in patients hospitalized from heart failure. BMC Cardiovasc Disord 2015;15:88.

15. Radulović $B$, Potočnjak I, Dokoza Terešak S, et al. Hypochloraemia as a predictor of developing hyponatraemia and poor outcome in acute heart failure patients. Int J Cardiol 2016;212:237-41.

16. Park JJ, Cho YJ, Oh IY, et al. Short and long-term prognostic value of hyponatremia in heart failure with preserved ejection fraction versus reduced ejection fraction: An analysis of the Korean Acute Heart Failure registry. Int J Cardiol 2017;248:239-45.

17. Jao GT, Chiong JR. Hyponatremia in acute decompensated heart failure: mechanisms, prognosis, and treatment options. Clin Cardiol 2010;33:666-71.

18. Gheorghiade M, Abraham WT, Albert NM, et al. Relationship between admission serum sodium concentration and clinical outcomes in patients hospitalized for heart failure: an analysis from the OPTIMIZEHF registry. Eur Heart J 2007;28:980-8.

19. Damman K, Testani JM. The kidney in heart failure: an update. Eur Heart J 2015;36:1437-44.

20. Ruggenenti P, Remuzzi G. Worsening kidney function in decompensated heart failure: treat the heart, don't mind the kidney. Eur Heart J 2011;32:2476-8

21. Breidthardt T, Weidmann ZM, Twerenbold R, et al. Impact of haemoconcentration during acute heart failure therapy on mortality and its relationship with worsening renal function: Haemoconcentration during acute heart failure therapy. European Journal of Heart Failure 2017;19:226-36.

22. Berra G, Garin N, Stirnemann J, et al. Outcome in acute heart failure: prognostic value of acute kidney injury and worsening renal function. $J$ Card Fail 2015;21:382-90.

23. Kataja A, Tarvasmäki T, Lassus J, et al. The association of admission blood glucose level with the clinical picture and prognosis in cardiogenic shock - Results from the CardShock Study. Int J Cardiol 2017;226:48-52.

24. Sud M, Wang X, Austin PC, et al. Presentation blood glucose and death, hospitalization, and future diabetes risk in patients with acute heart failure syndromes. Eur Heart J 2015;36:924-31.

25. Kattel S, Kasai T, Matsumoto $\mathrm{H}$, et al. Association between elevated blood glucose level on admission and long-term mortality in patients with acute decompensated heart failure. J Cardiol 2017;69:619-24.

26. Lee DS, Stitt A, Austin PC, et al. Prediction of heart failure mortality in emergent care: a cohort study. Ann Intern Med 2012;156:767-75.

27. Danchin N, Puymirat E, Steg PG, et al. Five-year survival in patients with ST-segment-elevation myocardial infarction according to modalities of reperfusion therapy: the French Registry on Acute STElevation and Non-ST-Elevation Myocardial Infarction (FAST-MI) 2005 Cohort. Circulation 2014;129:1629-36.

28. Logeart D, Thabut G, Jourdain P, et al. Predischarge B-type natriuretic peptide assay for identifying patients at high risk of re-admission after decompensated heart failure. J Am Coll Cardiol 2004:43:635-41.

29. Fonarow GC, Peacock WF, Phillips CO, et al. ADHERE Scientific Advisory Committee and Investigators. Admission B-type natriuretic peptide levels and in-hospital mortality in acute decompensated heart failure. J Am Coll Cardiol 2007;49:1943-50.

30. Pascual-Figal DA, Casas T, Ordonez-Llanos J, et al. Highly sensitive troponin $\mathrm{T}$ for risk stratification of acutely destabilized heart failure. Am Heart J 2012;163:1002-10.

31. Walker AS, Mason A, Quan TP, et al. Mortality risks associated with emergency admissions during weekends and public holidays: an analysis of electronic health records. Lancet 2017;390:62-72.

32. Passantino A, Monitillo F, lacoviello M, et al. Predicting mortality in patients with acute heart failure: Role of risk scores. World J Cardiol 2015;7:902-11. 